Original scientific paper

\title{
GO-KART CHASSIS DESIGN USING FINITE ELEMENT ANALYSIS AND MULTIBODY DYNAMIC SIMULATION
}

\author{
Sampayo, D.; Luque, P.; Mantaras, D. A. \& Rodriguez, E. \\ Transportation Engineering, Oviedo University - Campus de Gijón, 33203 Gijón, Spain \\ E-Mail: luque@uniovi.es
}

\begin{abstract}
For the accurate design of some types of mechanisms, it is necessary to combine multibody dynamics computer simulations with finite element structural analysis. These types of mechanisms are the multibody mechanisms in which the body (frame) stiffness of some of the bodies have the same magnitude as some of their elastic elements. With this in mind, the traditional go-kart chassis design process is reviewed. The traditional approach to evaluate the structural properties of its frame consists of an iterative process in which FEM techniques are applied considering constant load cases. These load cases are defined according to the maximum stresses to which it will be subjected during its operation (circulation in a race circuit). However, as it will be proven in this work, the load case will depend on the design of the frame itself. Due to the stiffness of the frame, for the same driving conditions (vehicle trajectory and speed) the structural load condition varies significantly. A design methodology is proposed for this type of system that combines multibody simulation and finite elements.

(Received in December 2020, accepted in April 2021. This paper was with the authors 1 month for 2 revisions.)
\end{abstract}

Key Words: Go-Kart, Finite Element Analysis, Multibody Dynamics

\section{INTRODUCTION}

Nowadays, land vehicle design is performed using Computer Aided Engineering tools [1]. To analyse the behaviour of those vehicles when different input conditions are imposed, computer dynamic simulation techniques are typically used [2]. On the other hand, when referring to structural design of different kind of vehicles, the common method applied is the Finite Element Method (FEM). In [3] the authors present a methodology for the structural optimization of a rally vehicle in relation to passive safety. Another example [4], apply explicit solvers of FEM models for the analysis of protection systems installed on roads and circuits. In [5], the authors show that optimum design of structures under multiple load cases can be determined using finite element method. Vibrations and resonance effects can be analysed with this method as shown in [6]. Consideration of body forces within Finite Element Analysis are studied in [7]. The FEM is applied to get the resulting stress and strain from different load cases that are imposed as boundary conditions [8]. These boundary conditions are quasi-static loads that reproduce the maximum stresses in a given circuit [9]. These loads are increased to meet regulation and technical specifications but are considered as constant [10]. The load cases come from static studies of the vehicles that are designed as shown in [11] and [12]. This is the design procedure commonly used in go-kart vehicles, with several examples. For instance, [13] includes frontal and side impact conditions while [14] includes frontal rear and side impact conditions. Other authors [15] and [16] additionally study the response to vertical static loads. FEM has been used for other structural studies of parts related to vehicle systems, such as brakes [17] or suspension and steering elements [18]. In state of art, the load cases are considered as constant. Subsequently, they are not modified with the redesigns of the structure. It also has to be mentioned that test and instrumentation techniques are used with the purpose of improving these methods' fidelity [9]. What it is relevant to find out when performing these tests are the actual conditions in which the vehicle will be operating. It is also studied the cooperation among simulation and models based on data [19]. The mentioned techniques had been used to optimize 
the sports vehicles' performance, from the highest to the lowest categories [20]. However, performing a vehicle dynamic computer simulation implies having a vast knowledge of many aspects as mechanisms [21] or mechatronics systems [22] as powertrain [23], steering and suspension [24] and the tire-road interaction. Virtual tests simulations are performed to minimize the cost and time spent on performance evaluation phases [25].

Nowadays, vehicle dynamics simulations are combined with FEM analysis to include the effect of structural deformations during the dynamic simulation. Integrated multi-body / FEM analysis is also applied in fields as diverse as hydraulics [26, 27] or measuring devices [28]. Zeng $[26,27]$ analyses the effect of the bodies stiffness on the loads transmitted to the joints in a sliding block-type support implemented in ADAMS. Cuesta [28] calculates the measurement error of coordinate measuring arms due to its dynamic deformations.

Throughout this work, a new approach to the design process of a go-kart vehicle is shown. A go-kart is a single-seater four-wheel land vehicle, typically rear-wheel drive and without a suspension system. The design needs to be adapted to the Commission Internationale de Karting-FIA (CIK-FIA) international regulations [29]. It has to be noticed that there are many different works in which the structure is designed through FEM and dynamic response is evaluated separately afterwards, as previously cited. However, due to the lack of a suspension system, the chassis stiffness becomes a major issue when referring to the dynamic performance of the vehicle [30]. Therefore, there are cases where the influence of structural stiffness is important in the design of a go-kart vehicle.

On the one hand, the go-kart frame needs to be flexible enough to absorb part of the vibrations that the suspension system would have absorbed. On the other hand needs to be rigid enough to overcome the loads that will appear during its normal use. Therefore, depending on the stiffness of the frame, the load condition varies. It can be assumed that for a given dynamic condition the load case will be a function of the frame stiffness. Therefore, it is not acceptable to size or optimize a frame with a constant load case.

Considering this hypothesis, a methodology is proposed for the structural design of a gokart. The proposed methodology combines finite element analysis (using ANSYS ${ }^{\mathbb{R}}$ ) [31] and multibody dynamics (using ADAMS ${ }^{\circledR}$ ) [32], in order to get a multibody dynamic analysis which considers the designed chassis as a flexible body. The deformations and vibrations that occur under driving conditions are also taken into account. This allows to check if the frame stiffness influences the load case, as it was supposed.

Despite the fact that are some works in which go-kart dynamics are analysed, the simplicity of the models and the manoeuvres report low-detailed results. A detailed model and complex manoeuvres (similar to real manoeuvres) are needed to perform a simulation to get accurate results of the dynamic behaviour and the frame load case.

The white paper analyses the dynamic response by using computer simulation both considering rigid and flexible bodies. As will be shown, the load cases depend on the frame stiffness. So, the load case use as input in FEM calculation must be obtained from a multibody dynamic simulation. Traditionally, design and validation are done against a single load case, assuming it does not change depending on the design.

The original contribution of this work is a new design methodology that includes the flexible effect of the structure on the determination of the load case. This iterative methodology is implemented in the process of designing and assessing go-kart vehicles.

\section{METHODOLOGY}

In the traditional approach, the initial step of the design process is to create a first design of the chassis elements, and then adapt it to commercial parts to get a complete model of the vehicle. The chassis dimensions and materials must comply with FIA Regulations. It must have enough 
space for the rest of the parts attached to the frame and has to be able to withstand the dynamic loads that appear while racing.

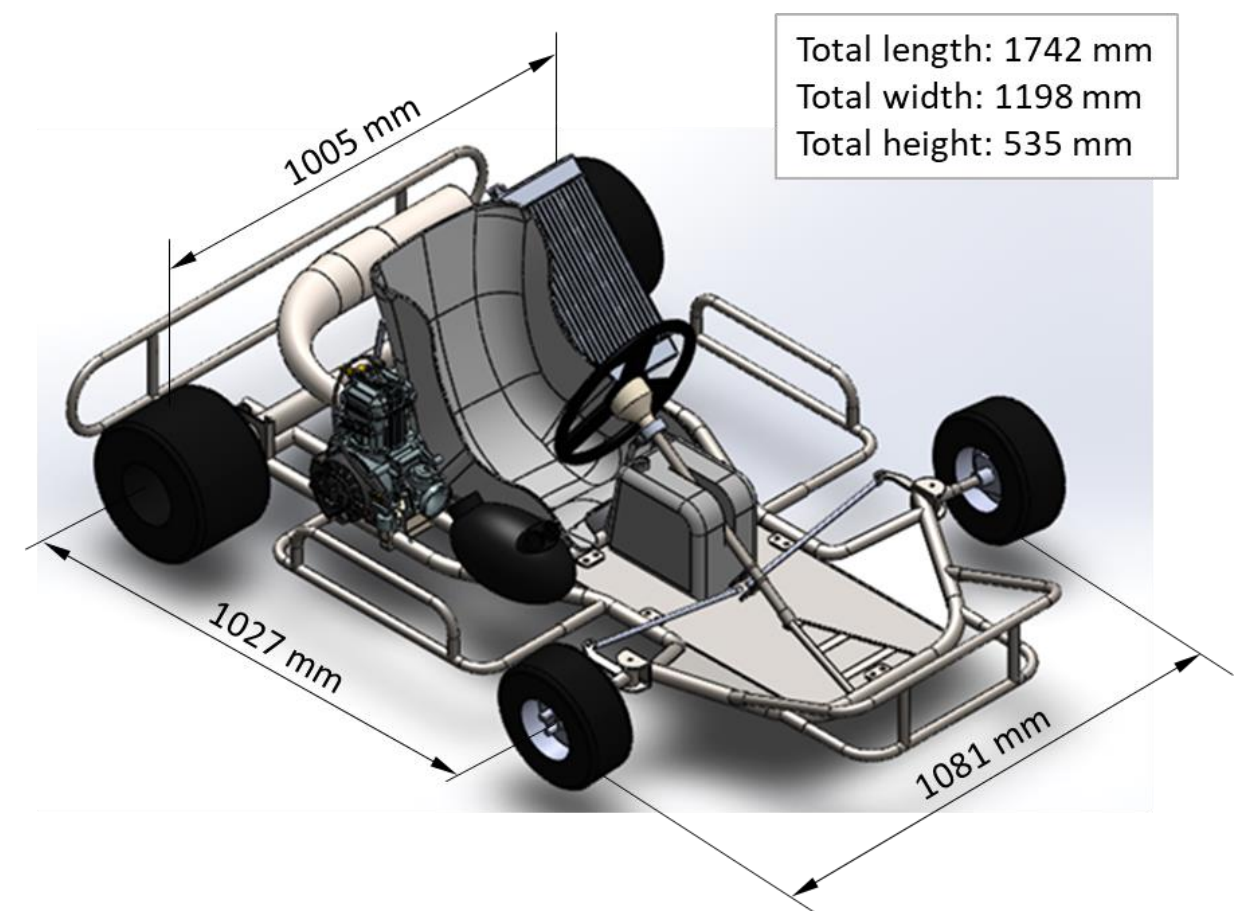

Figure 1: Vehicle 3D model.

At the end of this step, a complete preliminary model of a go-kart vehicle is obtained (Fig. 1). This model includes both designed parts and other commercial parts. The following task is to check if the dimensions of the complete vehicle fulfil the regulations. Once checked that the dimensions are correct, a FEM analysis of the frame should be performed (Fig. 2). The calculation and optimization process involves the introduction of a determined load case and the characterization of the material's properties. Once the simulation is put forward, a set of results including stress, strain, and deformation are obtained. These results must be compared to frame design specifications.
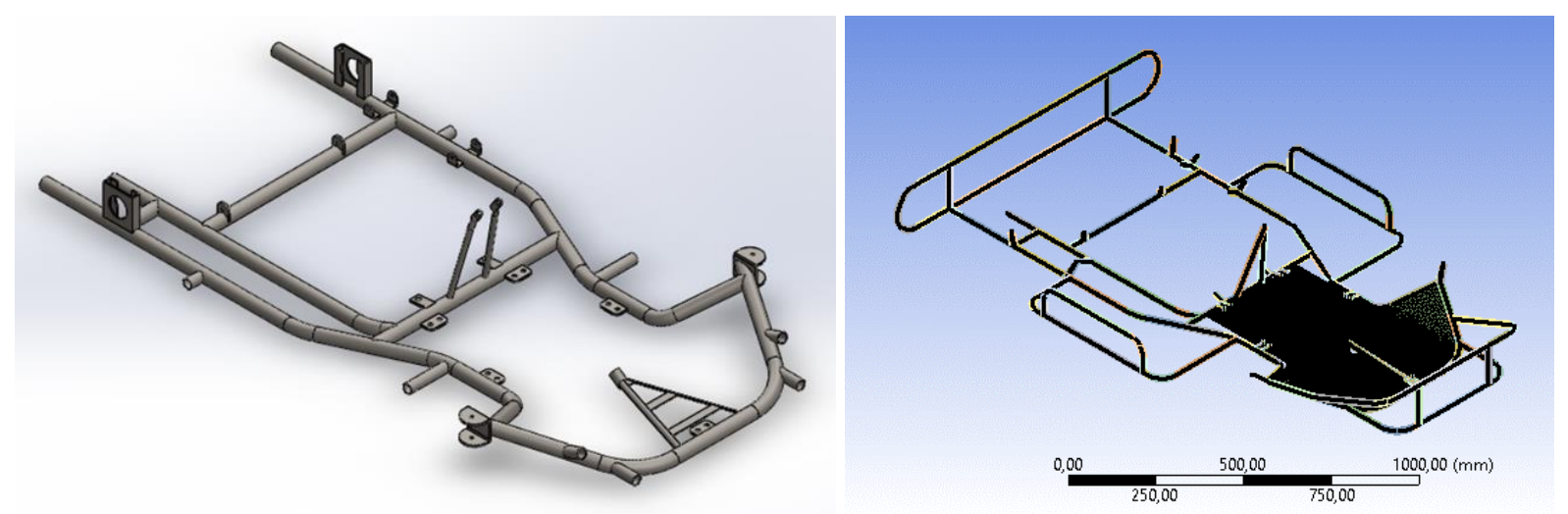

Figure 2: Vehicle frame concept (left), FEM model (right).

Implementing an iterative optimization process with feedback allows reaching a final solution to the problem. However, as mentioned, this process involves the introduction of a load case. Those loads are supposed to be constant during the whole process (Fig. 3). An example of these imposed load cases are the torsional cases (Fig. 4) or vertical and lateral bending. 


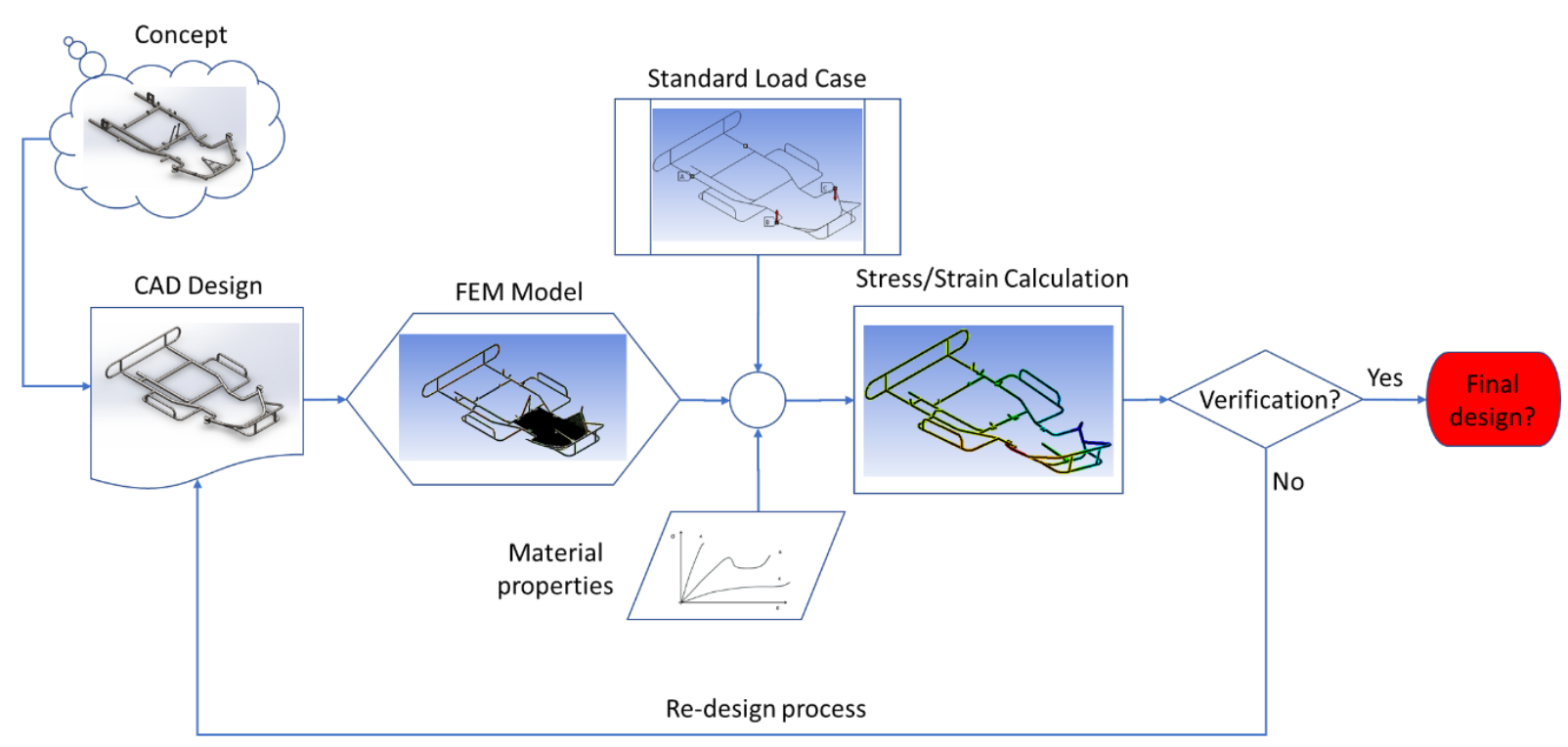

Figure 3: Common feedback optimization process.

If, for instance, a torsional load case is defined to perform the FEM analysis, these conditions will simulate the cornering conditions on a given curve. This load case can be simulated with two opposite forces applied in the front part of the frame while the rear part is fixed. This load case and results are depicted in Fig. 4.
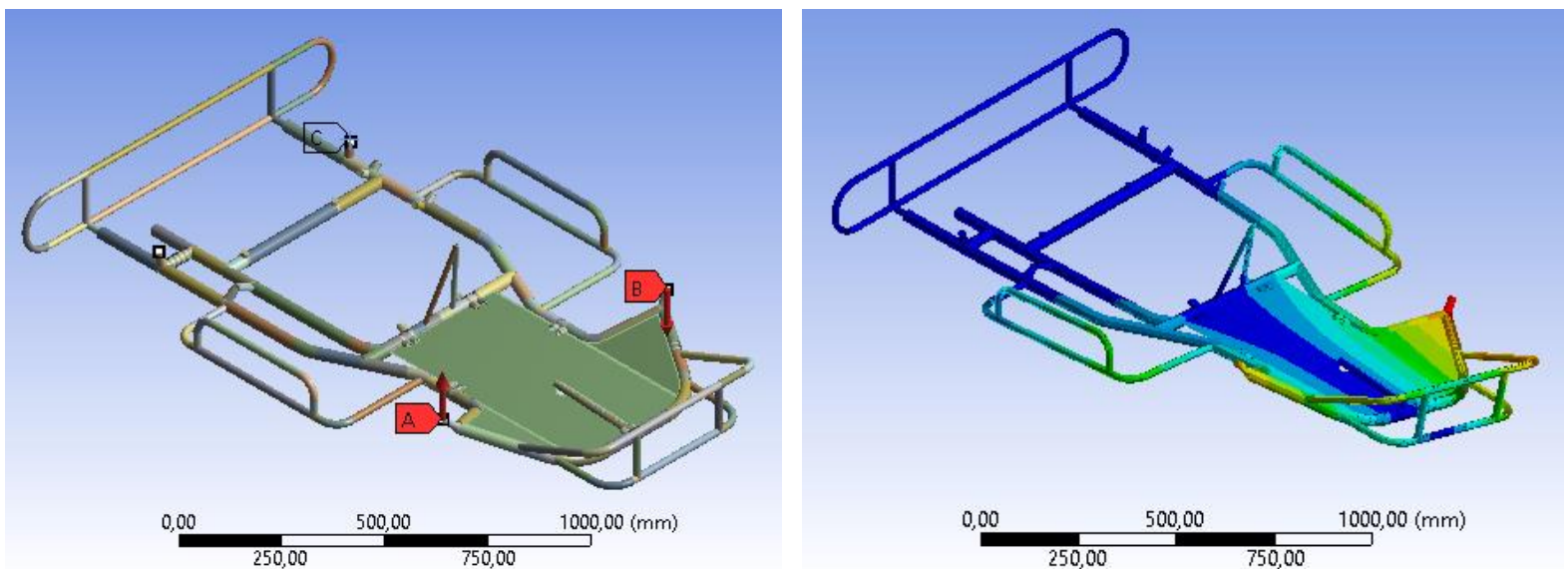

Figure 4: Structure under torsional load case.

As stated earlier in the introduction, many references are using this methodology. However, the go-kart vehicles do not have a suspension system based on springs and dampers actuating between the wheels and the structure. Due to this lack, the frame stiffness will characterize the dynamic response of the vehicle, concluding that the traditional methodology is not adequate to solve this kind of problems.

A different methodology (Fig. 8) is proposed in order to solve the challenge of go-kart frame design. In this methodology, the effects of the frame stiffness are considered to get a new load case definition. This methodology is implemented in a study case.

This methodology is based on the development of a model that combines multibody dynamic and the FEM simulation, with the aim of obtaining a multibody dynamic model that considers the flexibility of the frame. An example of a multibody dynamics software is ADAMS $^{\circledR}$ [32]. This kind of tools can simulate the dynamic response of a group of rigid bodies related through a series of constrains and exposed to different dynamic or kinematic inputs. To perform this simulation, a full vehicle model must be created as shown in Fig. 5. 


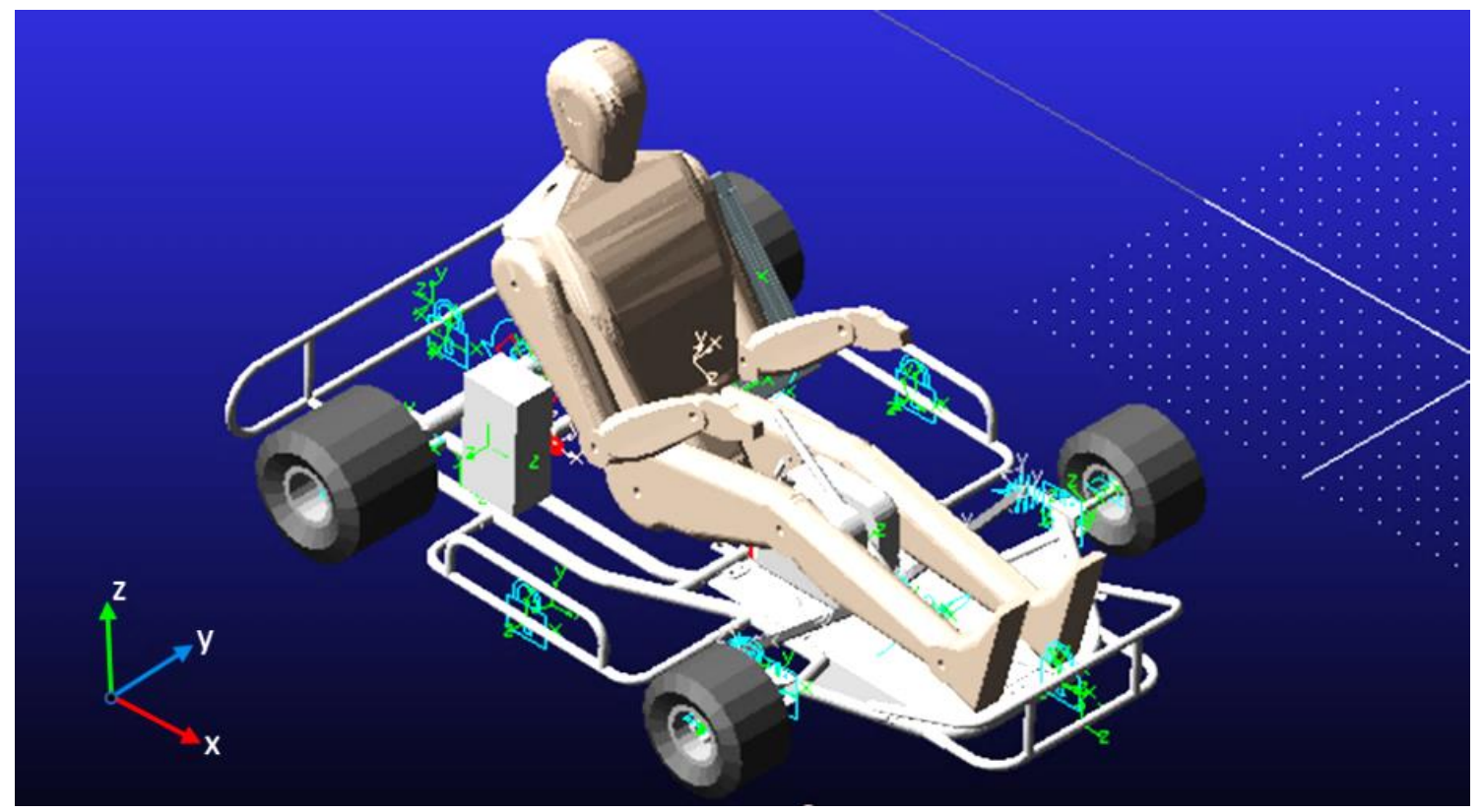

Figure 5: Rigid multibody dynamic model, 25 moving parts model with 21 degrees of freedom.

In addition to the model, the vehicle trajectory, speed, and acceleration must be defined to perform the computer simulation. In this case, the trajectory chosen was based on the racing circuits in which this type of vehicles competes. Those circuits contain low and high-speed corners as well as linked corners. The full trajectory defined (Fig. 6) contains two low-speed corners (one right and one left), other two high-speed corners (also one right and one left), and a slalom. Referring to speed and acceleration (Fig. 7), the first straight contains an acceleration from $0 \mathrm{~km} / \mathrm{h}$ to $120 \mathrm{~km} / \mathrm{h}$ and the last straight contains a heavy breaking from $100 \mathrm{~km} / \mathrm{h}$ to 0 $\mathrm{km} / \mathrm{h}$, meanwhile the speed during the corners is constant $(50 \mathrm{~km} / \mathrm{h}$ in the case of low speed corners and $100 \mathrm{~km} / \mathrm{h}$ in the case of high-speed ones).

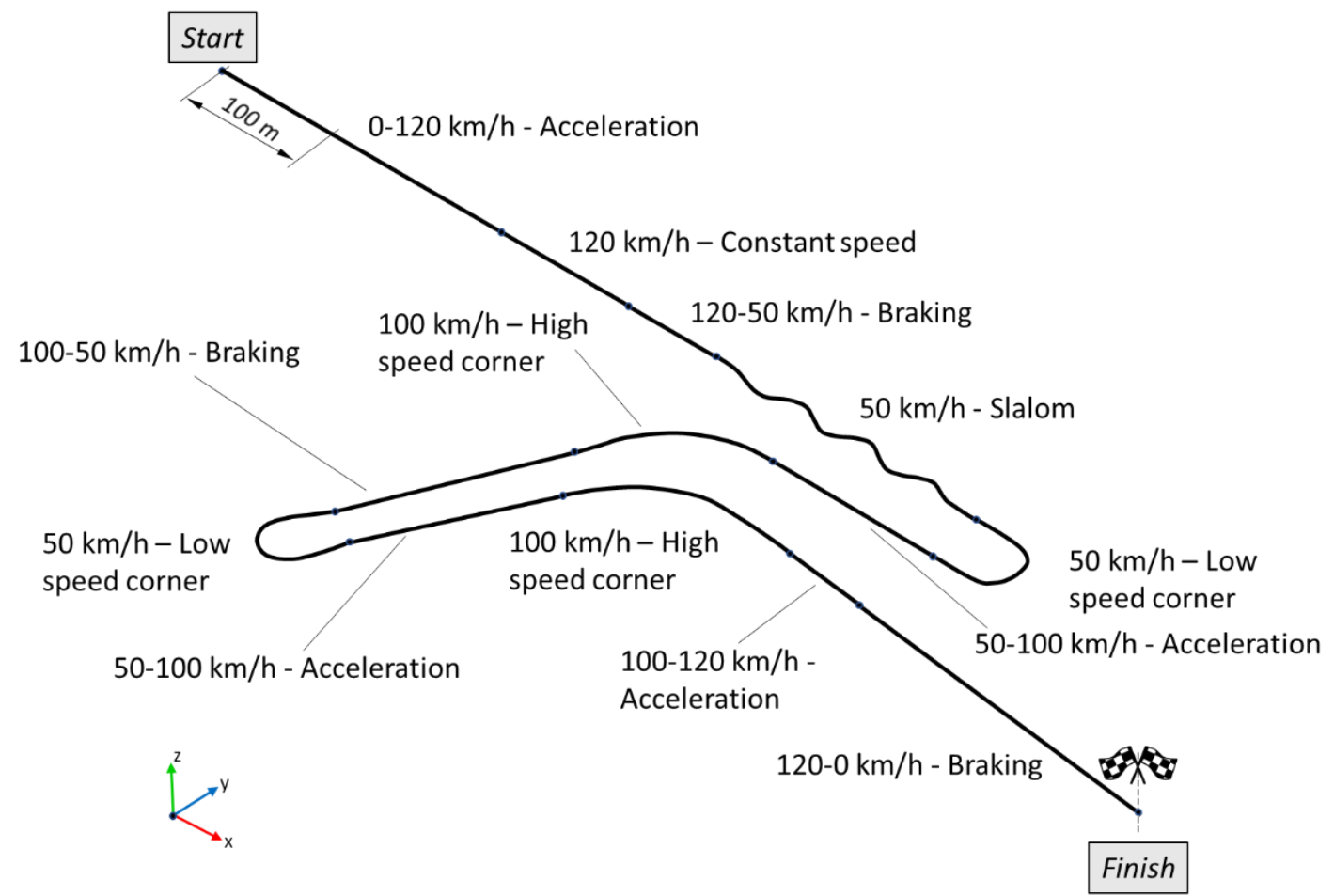

Figure 6: Vehicle trajectory. 


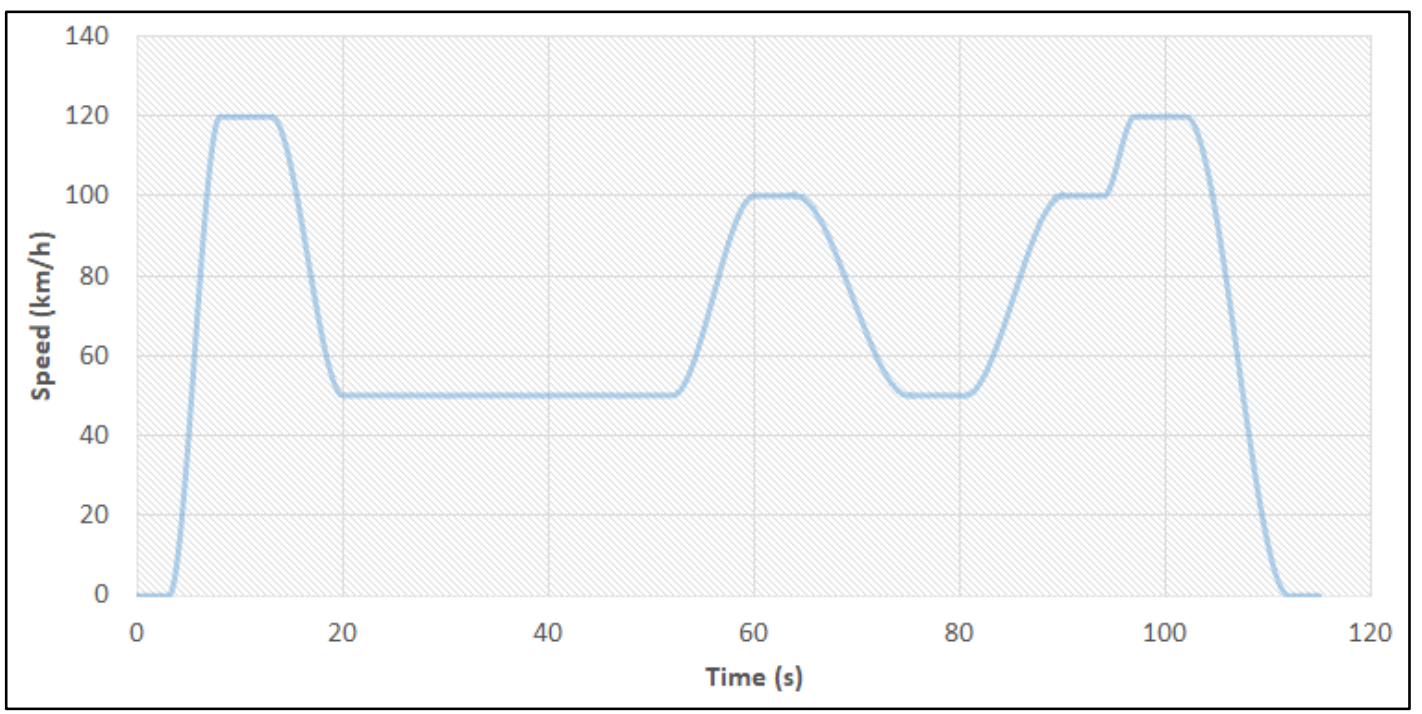

Figure 7: Vehicle's longitudinal speed $(\mathrm{km} / \mathrm{h})$ vs time $(\mathrm{s})$.

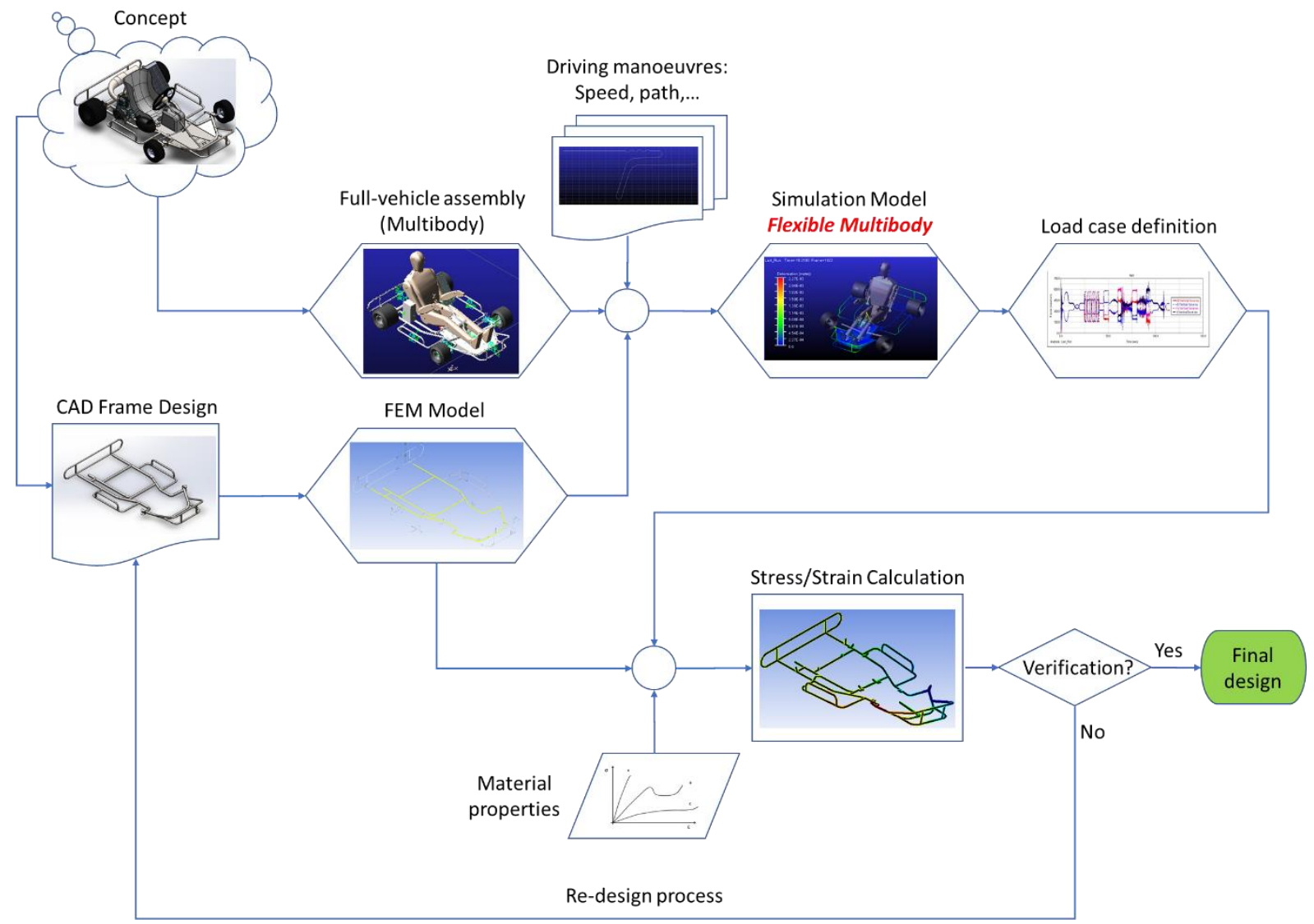

Figure 8: Proposed methodology for chassis design and optimization.

The proposed methodology is based on the development of a model that combines multibody dynamic and the FEM simulation, with the aim of obtaining a multibody dynamic model that considers the flexibility of the frame.

The initial FEM model of the multi-tube frame is composed of 26,943 beam elements (BEAM1) of an average size of $1 \mathrm{~mm}$, with 53,579 nodes. The front plate is composed of 8918 shell elements (SHELL181) of $15 \mathrm{~mm}$ size, with 13407 nodes. The material is an AISI 4130 steel with a Young's modulus of $2.05 \mathrm{E}+11 \mathrm{~Pa}$, Poisson's ratio 0.285 , yield stress $4.6 \mathrm{E}+8 \mathrm{~Pa}$ and ultimate stress 7.31E $+8 \mathrm{~Pa}$. From the FEM model, a modal neutral file is exported. This 
file contains the flexibility information of the component and includes geometry, nodal mass and inertia, mode shapes and generalized mass and stiffness for mode shapes. In the table I the first eleven modes of the body frame and front plate are shown.

Table I: Forces and torques obtained in different frame designs.

\begin{tabular}{|c|c|c|}
\hline Mode & Body frame $(\mathrm{Hz})$ & Front plate $(\mathrm{Hz})$ \\
\hline 1 & 35.70 & 47.24 \\
\hline 2 & 40.480 & 51.83 \\
\hline 3 & 70.14 & 117.38 \\
\hline 4 & 72.47 & 131.36 \\
\hline 5 & 82.59 & 145.83 \\
\hline 6 & 94.17 & 184.67 \\
\hline 7 & 100.17 & 212.89 \\
\hline 8 & 111.52 & 258.98 \\
\hline 9 & 119.49 & 275.57 \\
\hline 10 & 125.14 & 345.58 \\
\hline 11 & 127.84 & 417.63 \\
\hline
\end{tabular}

The multibody model was generated in ADAMS-View. It has 19 Moving Parts (not including ground), 2 Flexible_Bodys, 8 Revolute Joints, 4 Spherical Joints, 19 Fixed Joints and 2 Motions. The total mass is $187 \mathrm{~kg}$.

Once obtained the model (denoted as flexible multibody in Fig. 8), it is simulated by implementing the same trajectory, speed, and acceleration conditions as the rigid original multibody model. With the results of this simulation, a new load case for the FEM analysis could be defined to get the new stress and strain results and continue with the optimization process.

It has to be noticed that, in contrast with the traditional methodology, the load case will not be constant. This load case, which depends on the topology and mechanical properties of the frame, is more faithful to the real driving conditions than the traditional approach.

\section{RESULTS AND DISCUSSION}

Throughout this section, the previously commented design methodology is applied. Firstly, the full-vehicle assembly is simulated without taking into consideration the structure's flexibility (stiffness). Through this simulation, a "rigid" load case is defined at every simulation step, and the worst case is selected to perform the FEM simulation and evaluate the stress and strain at this particular simulation step.

The load case is defined by a set of forces and torques applied to the frame. The forces and torques are applied at the joints and constraints that relate the frame to the rest of the vehicle's components. Particularly, this body (frame) is in contact with other parts at 13 different hard points denoted as Fig. 9:

- A, B: knuckle revolute joint,

- C, D: rear axle revolute joint,

- E, F, G, H: seat and driver bushing,

- I, J: radiator attachment,

- K: engine attachment,

- L, M: steering column revolute joint. 


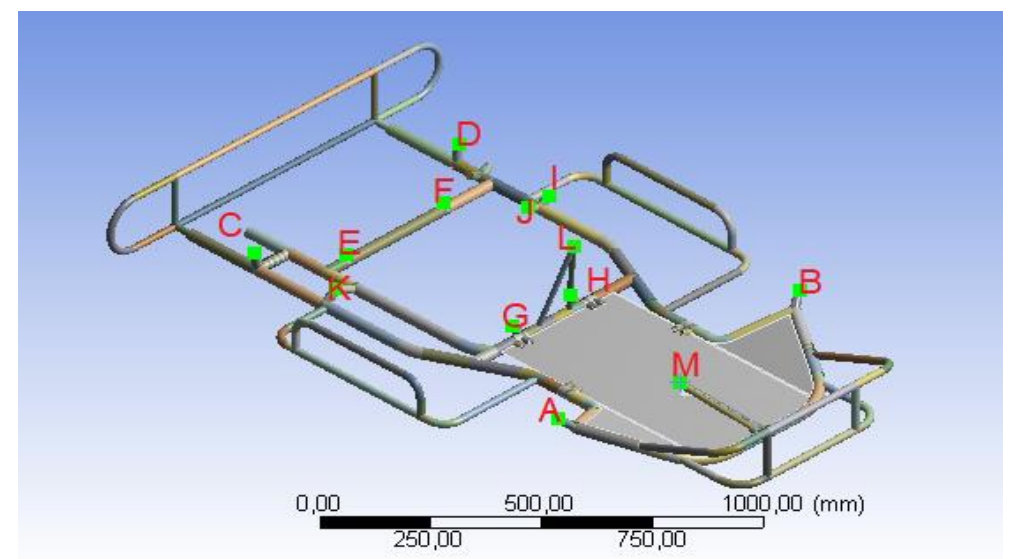

Figure 9: Points where a joint or constraint is applied.

After performing the dynamic analysis, and once introduced the load case into the FEM software, the result is that the maximum stress does not surpass the design constraints (for instance material's yield strength, safety factor...), meaning that the design could be considered as valid.

Nevertheless, continuing with the proposed methodology, a new dynamic simulation is performed, but taking into consideration this time the frame's flexibility (Fig. 10, left). A new load case is obtained. This flex load case is used as input in FEM analysis (Fig. 10, right). The result is that, as expected, the load varied, but surprisingly, it varied until the point that now the model becomes invalid because the maximum Von-Mises stress is surpassing a prefixed value. The design does not fulfil the dynamic specifications.
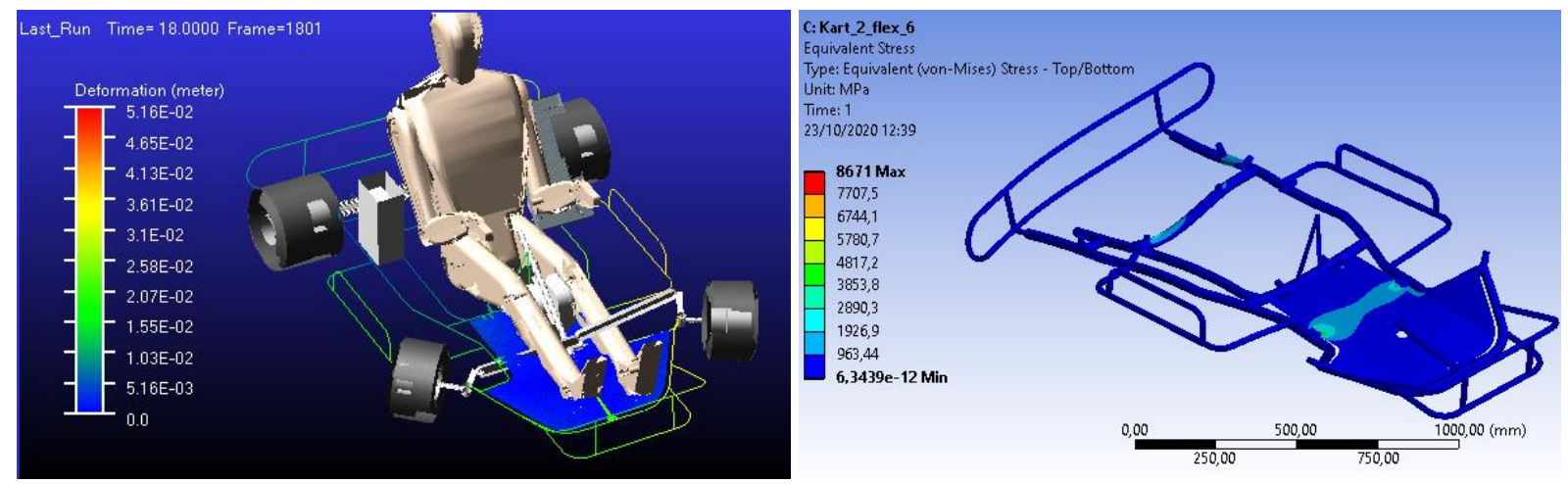

Figure 10: Deformation result during dynamic simulation (left), Von-Mises stress output from FEM analysis under flexible load case (right).

To clearly evidence this phenomenon, some force and torque values obtained as results of multibody simulation are shown in Table II. Those values are calculated under the same simulation conditions, according to global reference frame depicted in Fig. 5. The simulation point (time step) selected is that in which the loads in selected hard points are the highest. Those selected hard points (depicted at Fig. 9) are the knuckle revolute joints (A, B), and the rear axle revolute joints $(\mathrm{C}, \mathrm{D})$. The different load cases are denoted as "Rigid" if the flexibility of the structure is not considered, and as "Flex" if it is.

The selected location in the simulation is a curve to the right. The running speed is $13.27 \mathrm{~m} / \mathrm{s}$, the lateral acceleration is $7.8 \mathrm{~m} / \mathrm{s}^{2}$ and it generates a yaw rate of $34 \%$ s. Vehicle speed is entered into the multibody model by means of a driver on the drive axle (rear), which includes feedback control of speed based on dynamic response.

To evaluate the effect of flexibility in multibody simulation, other structural configurations with different stiffness are proposed. The usual value of stiffness in this type of vehicle is 
torsional stiffness. To obtain this value, the developed FEM models are used. On these models, the rear hard points (anchors $\mathrm{C}$ and D) are fixed and frontal torque applied. Two vertical forces configure the torque, equal in direction and modulus, but in the opposite direction. These forces are applied at hard points $\mathrm{A}$ and $\mathrm{B}$.

As an example (case study) of the present methodology, the results corresponding to various designs are presented. The designs modify the topology and the section of the tubes that make up the structure. It is not the object of this work to detail the designs or the criteria for structural modification. Only their torsional rigidity will be characterized. The characteristic values of stiffness are shown below:

- Flex - Torsional stiffness: $1051 \mathrm{Nm} /{ }^{\circ}$,

- Flex2 - Torsional stiffness: $1625 \mathrm{Nm} /{ }^{\circ}$,

- Flex3 - Torsional stiffness: $2314 \mathrm{Nm} /{ }^{\circ}$,

- Flex4 - Torsional stiffness: $3464 \mathrm{Nm} /{ }^{\circ}$.

Table II: Forces and torques obtained in different frame designs, according to coordinate system in Fig. 5.

\begin{tabular}{|c|c|c|c|c|c|c|}
\cline { 3 - 7 } \multicolumn{2}{c|}{} & \multicolumn{6}{c|}{ Load case } \\
\hline \multirow{4}{*}{ Node } & $\begin{array}{c}\text { Forces and } \\
\text { torques }\end{array}$ & Rigid & Flex & Flex 2 & Flex 3 & Flex 4 \\
\hline \multirow{4}{*}{ A } & $F_{x}(\mathrm{~N})$ & $\mathbf{- 2 7 . 2}$ & -29.4 & -28.3 & -27.3 & -27.0 \\
\cline { 2 - 7 } & $F_{y}(\mathrm{~N})$ & $\mathbf{- 2 6 6 . 6}$ & -270.8 & -269.0 & -270.4 & -266.1 \\
\cline { 2 - 7 } & $F_{z}(\mathrm{~N})$ & $\mathbf{2 5 2 . 8}$ & 254.7 & 245.7 & 252.1 & 249.7 \\
\cline { 2 - 7 } & $M_{x}(\mathrm{~N} \cdot \mathrm{m})$ & $\mathbf{- 7 9 . 6}$ & -87.6 & -86.4 & -86.9 & -85.7 \\
\cline { 2 - 7 } & $M_{y}(\mathrm{~N} \cdot \mathrm{m})$ & $\mathbf{5 . 9}$ & 7.0 & 6.9 & 7.0 & 6.9 \\
\cline { 2 - 7 } & $M_{z}(\mathrm{~N} \cdot \mathrm{m})$ & $\mathbf{0}$ & 0 & 0 & 0 & 0 \\
\hline \multirow{4}{*}{ B } & $F_{x}(\mathrm{~N})$ & $\mathbf{- 5 8 . 5}$ & -54.4 & -55.0 & -55.2 & -55.7 \\
\cline { 2 - 7 } & $F_{y}(\mathrm{~N})$ & $\mathbf{- 6 0 1 . 9}$ & -518.2 & -520.2 & -520.1 & -521.7 \\
\cline { 2 - 7 } & $F_{z}(\mathrm{~N})$ & $\mathbf{5 5 6 . 3}$ & 547.0 & 555.6 & 550.0 & 551.4 \\
\cline { 2 - 7 } & $M_{x}(\mathrm{~N} \cdot \mathrm{m})$ & $\mathbf{2 0 . 6}$ & 5.3 & 5.5 & 5.3 & 5.5 \\
\cline { 2 - 7 } & $M_{y}(\mathrm{~N} \cdot \mathrm{m})$ & $\mathbf{- 9 . 9}$ & -0.8 & -0.8 & -0.8 & -0.9 \\
\cline { 2 - 7 } & $M_{z}(\mathrm{~N} \cdot \mathrm{m})$ & $\mathbf{0}$ & 0 & 0 & 0 & 0 \\
\hline \multirow{4}{*}{ C } & $F_{x}(\mathrm{~N})$ & $\mathbf{1 1 3 . 1}$ & 261.2 & 220.3 & 253.8 & 261.6 \\
\cline { 2 - 7 } & $F_{y}(\mathrm{~N})$ & $\mathbf{- 2 6 6 . 1}$ & -294.8 & -311.0 & -273.6 & -261.9 \\
\cline { 2 - 7 } & $F_{z}(\mathrm{~N})$ & $\mathbf{2 9 2 . 8}$ & 312.9 & 303.3 & 316.2 & 321.4 \\
\cline { 2 - 7 } & $M_{x}(\mathrm{~N} \cdot \mathrm{m})$ & $\mathbf{- 1 4 . 4}$ & 25.5 & 18.8 & 27.3 & 28.2 \\
\cline { 2 - 7 } & $M_{y}(\mathrm{~N} \cdot \mathrm{m})$ & $\mathbf{0}$ & 0 & 0 & 0 & 0 \\
\cline { 2 - 7 } & $M_{z}(\mathrm{~N} \cdot \mathrm{m})$ & $\mathbf{8 7 . 2}$ & 3.5 & 15.5 & 1.8 & -0.5 \\
\hline \multirow{4}{*}{$\mathbf{D}$} & $F_{x}(\mathrm{~N})$ & $\mathbf{3 . 2}$ & -146.3 & -119.0 & -152.2 & -160.7 \\
\cline { 2 - 7 } & $F_{y}(\mathrm{~N})$ & $\mathbf{- 2 6 6 . 1}$ & -256.4 & -226.8 & -274.7 & -275.0 \\
\cline { 2 - 7 } & $F_{z}(\mathrm{~N})$ & $\mathbf{5 7 1 . 8}$ & 565.1 & 571.2 & 558.6 & 553.0 \\
\cline { 2 - 7 } & $M_{x}(\mathrm{~N} \cdot \mathrm{m})$ & $\mathbf{- 1 5 . 0}$ & -32.6 & -34.4 & -33.0 & -31.7 \\
\cline { 2 - 7 } & $M_{y}(\mathrm{~N} \cdot \mathrm{m})$ & $\mathbf{0}$ & 0 & 0 & 0 & 0 \\
\cline { 2 - 7 } & $M_{z}(\mathrm{~N} \cdot \mathrm{m})$ & $\mathbf{8 7 . 2}$ & 2.5 & 10.5 & 0.5 & 0.1 \\
\hline
\end{tabular}

In Table II, it can be seen that the rigidity modifications affect the load cases. Flexible models capture local effects in which design conditions can be exceeded. These local effects cannot be analysed with a load case from a rigid multibody simulation. It can be verified by modifying the structural rigidity; the obtained values can vary up to over $20 \%$ of those obtained in the rigid case. It can also be concluded that, although the overall stiffness is significantly increased, the stress state obtained with flexible is not the same as that obtained for a rigid one.

The different simulations shown in Table II were part of a redesign process. This redesign process is activated due to the invalidity of the first model when evaluated through flexible dynamics. The different redesigned models were simulated directly with flexible dynamics and following the proposed iterative methodology. The original frame and parts designed where 
changed in order to stiffen the whole structure. The changes made (Fig. 11) include changing the cross section of the tubes, changing the material into a higher Young's modulus (using AISI 4150 despite of AISI 4130), adding reinforcement tubes, and simplifying the floor's geometry. Finally, the process stops when the structure (Fig. 12) complies the design specifications.
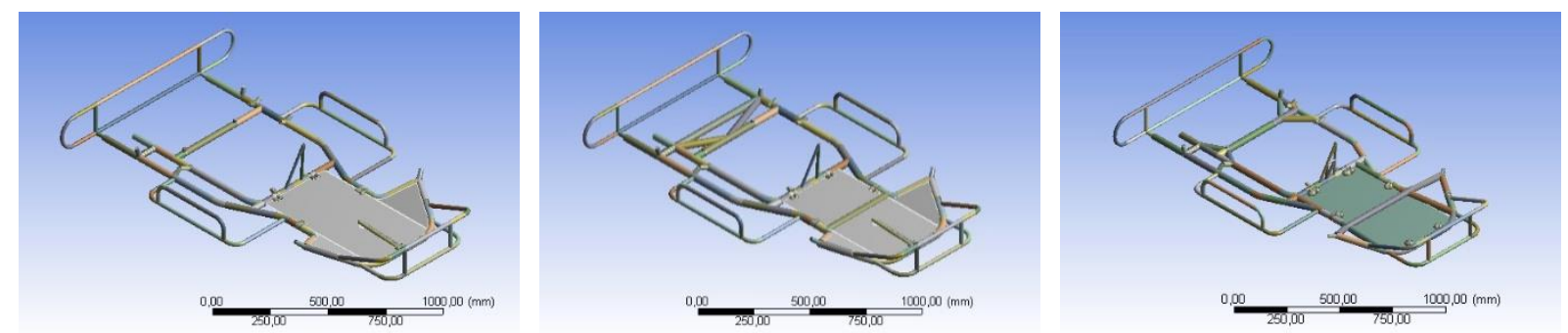

Figure 11: Different designs during the redesign process: Flex 2 (left), Flex3 (middle) and Flex4 (right).

After this process, it could be concluded, as it was supposed, that the load case varies significantly depending on the stiffness of the structure, and that taking into consideration the structure's flexibility really helps during the design process to get more realistic results.

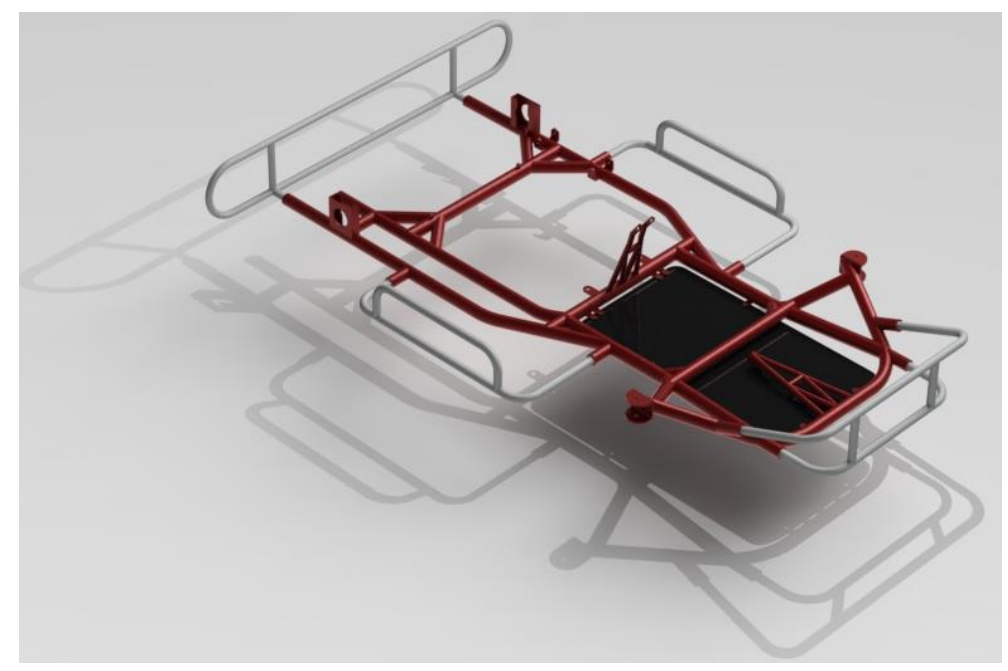

Figure 12: Final design rendered image.

\section{CONCLUSSIONS}

The traditional approach to evaluate the structural properties of a go-kart frame consists of an iterative process in which FEM techniques are applied considering a constant load case that comes from a multibody model in which every part is considered as rigid. It is not always acceptable to assume that the bodies of this system are rigid to get a load case, and this was shown.

What it is proposed to solve this kind of problems, in which the structural stiffness cannot be neglected, is an iterative methodology that involves a multibody dynamic computer simulation that includes the effects of the structure's flexibility. This effect is implemented by embedding a FEM model into the multibody dynamics model.

As an example of the proposed methodology, an analysis of the dynamic response of a gokart vehicle was performed. During this process, a set of driving manoeuvres were simulated. This set represents common racing conditions that this type of vehicles faces. Consequently, the simulation includes varied manoeuvres as fast corners or linked ones, combined with heavy braking or acceleration actions. Firstly, the behaviour of all the vehicle's components was considered as rigid, this simulation was performed to obtain a load case to evaluate the stress 
and strain state of the structure. Those obtained stresses and strains were valid according to the specifications defined, consequently the design could be considered valid.

In contrast, if the multibody simulation was performed including the effects of the frame's flexibility, the resultant stress state was significantly different, to the point that the design became invalid. As a result, the methodology proposed was applied to stablish a redesign process.

It is proven that, as previously stated, the stress state of the frame is not constant for every design, which means that the load case depends on the design. That implies the necessity of modelling a FEM model of every new design to evaluate their stress state with a multibody dynamics and FEM coupled simulation. As a conclusion, it could be said that on a design process of this kind of vehicles, the frame's flexibility is a major issue to consider when analysing the performance of them, so the proposed methodology could help the designer to get an accurate model that simulates the track conditions, helping to develop an optimised design. The proposed methodology should be applied for the accurate design of multibody mechanisms in which the stiffness of the frame has the same magnitude as its elastic elements.

\section{REFERENCES}

[1] Raphael, B.; Smith, I. F. C. (2013). Engineering Informatics: Fundamentals of Computer-Aided Engineering, $2^{\text {nd }}$ edition, John Wiley \& Sons, Chichester

[2] Blundell, M.; Harty, D. (2015). The Multibody Systems Approach to Vehicle Dynamics, $2^{\text {nd }}$ edition Elsevier, Amsterdam, doi:10.1016/C2012-0-07000-7

[3] Luque Rodriguez, P.; Alvarez Mántaras, A.; Martinez de Orueta, A. (2013). Passive safety assessment in rally vehicle using virtual crash test, Dyna, Vol. 88, No. 4, 453-461, doi: $10.6036 / 5443$

[4] Mantaras, D. A.; Luque, P. (2015). Assessing motorcyclist protection systems using finite element simulations, International Journal of Simulation Modelling, Vol. 14, No. 1, 110-120, doi:10.2507/IJSIMM14(1)10.294

[5] Özkal, F. M.; Cakir, F.; Arkun, A. K. (2016). Finite element method for optimum design selection of carport structures under multiple load cases, Advances in Production Engineering \& Management, Vol. 11, No. 4, 287-298, doi:10.14743/apem2016.4.227

[6] Cui, K.; Su, L. (2019). Dynamic finite element analysis of an elevated station-track structure coupled system under resonance, Technical Gazette, Vol. 26, No. 2, 449-456, doi:10.17559/TV20181213175649

[7] Glenk, C.; Hüter, F.; Billenstein, D.; Rieg, F. (2018). Consideration of body forces within finite element analysis, Strojniski vestnik - Journal of Mechanical Engineering, Vol. 64, No. 5, 303-309, doi:10.5545/sv-jme.2017.5081

[8] Saheb, H. S.; Kona, R. K.; Hameed, M. (2016). Design report of a go kart vehicle, International Journal of Engineering Applied Sciences and Technology, Vol. 1, No. 9, 95-102

[9] Luque, P.; Mántaras, D. A.; Pello, A. (2013). Racing car chassis optimization using the finite element method, multi-body dynamic simulation and data acquisition, Proceedings of the Institution of Mechanical Engineers, Part P: Journal of Sports Engineering and Technology, Vol. 227, No. 1, 3-11, doi:10.1177/1754337112444517

[10] Bobrowskii, A. V.; Zotov, A. V.; Rastorguev, D. A.; Gorokhova, D. A.; Ugarova, L. A. (2019). Analysis of the frame design of the subcompact racing car of go-kart class, IOP Conference Series: Materials Science and Engineering, Vol. 537, Paper 032078, 5 pages, doi:10.1088/1757$\underline{899 X / 537 / 3 / 032078}$

[11] Bala Subramanyam, P. N. V.; Vishnu Vardhan Reddy, B.; Sai Prem Suhas, J. B.; Ravi Teja, J. B. (2017). Design and static analysis of go-kart, International Journal of Pure and Applied Mathematics, Vol. 116, No. 6, 167-171

[12] Patil, N. R.; Kulkarni, R. R.; Mane, B. R.; Malve, S. H. (2014). Static analysis of go-kart chassis frame by analytical and SolidWorks simulation, International Journal of Scientific Engineering and Technology, Vol. 3, No. 5, 661-663 
[13] Mohite, G. R.; Korde, P. T.; Derkar, P. P.; Nimkar, N. M.; Tiwari, N. V. (2016). Design and static analysis of a go-kart chassis by ANSYS simulation, International Research Journal of Engineering and Technology, Vol. 3, No. 4, 1426-1428

[14] Kiral Lal, A. O. (2016). Design, analysis and fabrication of go-kart, International Journal of Scientific \& Engineering Research, Vol. 7, No. 4, 429-434

[15] Kharabi, A.; Kharabi, A. V.; Kharabi, A. H.; Kharabi, T.; Kale, M. (2019). Design and analysis of electric kid's car, International Journal of Research in Engineering, Science and Management, Vol. 2, No. 2, 570-572

[16] Kondala Rao, P.; Jagadish, C.; Abhishek, P.; Mutra, R. R. (2019). Design and static analysis of chassis used in go-kart, International Journal of Engineering Research \& Technology, Vol. 7, No. 3, Paper IJERTCONV7IS03012, 4 pages

[17] Rajkumar, M.; Soundar Rajan, M.; Queen, F. M. (2020). Design optimization and analysis of braking system of go-kart, International Journal of Engineering Research \& Technology, Vol. 9, No. 9, 558-563, doi:10.17577/IJERTV9IS090339

[18] Chauan, A.; Naagar, L.; Chawla, S. (2016). Design and analysis of a go-kart, International Journal of Aerospace and Mechanical Engineering, Vol. 3, No. 5, 29-37

[19] Kim, B. S.; Kim, T. G. (2019). Cooperation of simulation and data model for performance analysis of complex systems, International Journal of Simulation Modelling, Vol. 18, No. 4, 608-619, doi:10.2507/IJSIMM18(4)491

[20] Allonca, D.; Mantaras, D. A.; Luque, P.; Alonso, M. (2019). A new methodology to optimize a race car for inertial sports, Proceedings of the Institution of Mechanical Engineers, Part P: Journal of Sports Engineering and Technology, Vol. 233, No. 2, 312-323, doi:10.1177/17543337118823971

[21] Garcia de Jalon, J.; Bayo, E. (1994). Kinematic and Dynamic of Multibody Systems: The Real-Time Challenge, $1^{\text {st }}$ edition, Springer-Verlag, New York

[22] Karnopp, D. C.; Margolis, D. L.; Rosenberg, R. C. (2006). System Dynamics: Modelling and Simulation of Mechatronic Systems, $4^{\text {th }}$ edition, John Wiley \& Sons, Hoboken

[23] Kanchwala, H.; Luque Rodriguez, P.; Alvarez Mántaras, D.; Wideberg, J.; Bendre, S. (2017). Obtaining desired vehicle dynamics characteristics with independently controlled in-wheel motors: State of art review, SAE International Journal of Passenger Cars - Mechanical Systems, Vol. 10, No. 2, 413-425, doi:10.4271/2017-01-9680

[24] Callejo, A.; García de Jalón, J.; Luque, P.; Mantaras, D. A. (2015). Sensitivity-based, multiobjective design of vehicle suspension systems, Journal of Computational and Nonlinear Dynamics, Vol. 10, No. 3, Paper 031008, 9 pages, doi:10.1115/1.4028858

[25] Henning, K.-U.; Sawodny, O. (2016). Vehicle dynamics modelling and validation for online applications and controller synthesis, Mechatronics, Vol. 39, 113-126, doi:10.1016/ j.mechatronics.2016.08.010

[26] Zeng, X. T.; Meng, G. Y.; Zhou, J. H. (2018). Analysis on the pose and dynamic response of hydraulic support under dual impact loads, International Journal of Simulation Modelling, Vol. 17, No. 1, 69-80, doi:10.2507/IJSIMM17(1)412

[27] Zeng, X. T.; Meng, G. Y.; Zheng, K. (2019). Force transmission analysis of sliding block-type hydraulic support under impact loads, International Journal of Simulation Modelling, Vol. 18, No. 1, 100-111, doi:10.2507/IJSIMM18(1)466

[28] Cuesta, E.; Mantaras, D. A.; Luque, P.; Alvarez, B. J.; Muina, D. (2015). Dynamic deformations in coordinate measuring arms using virtual simulation, International Journal of Simulation Modelling, Vol. 14, No. 4, 609-620, doi:10.2507/IJSIMM14(4)4.311

[29] FIA - Homologation Regulation, from https://www.fiakarting.com/sites/default/files/202102/Reglement\%20d\%27Homologation\%202021.pdf, accessed on 12-04-2021

[30] Mirone, G. (2010). Multi-body elastic simulation of a go-kart: correlation between frame stiffness and dynamic performance, International Journal of Automotive Technology, Vol. 11, No. 4, 461469, doi:10.1007/s12239-010-0057-6

[31] ANSYS, from https://www.ansys.com, accessed on 12-04-2021

[32] MSC-ADAMS, from https://www.mscsoftware.com/product/adams, accessed on 12-04-2021 